\title{
Equity in Health: Conception of Professionals in the Primary Network of the Unified Health System

\section{Abstract}

Background: This study refers to the process of investigation about the doctrinal principle of fairness of the Unified Health System (SUS), through analysis of the theoretical and legal framework and the applicability thereof, specifically in Primary Health Care (APS) level, since it helps in monitoring and referring the population to other levels. The objective of this study was to verify the checked concepts about fairness in health on the speech of professionals working in the Family health's strategy in the city of Juazeiro do Norte-CE, Brazil.

Method: An analytical and cross-sectional study was conducted with a qualitative approach to obtain data that demonstrate how equity is perceived by professionals working in the Health Primary Level in Juazeiro do Norte, Ceará, Brazil. The sample included 18 professionals working in the direct assistance of family's health and who worked for at least six months in family health strategies. Data collection was performed by a previously structured guide with subjective questions, to assist the interview. For data analysis, we used the technique of Bardin (2009). The study followed all the provisions of the National Health Council Resolution 466/12 and Ministry of Health.

Results: It is possible to see that all employees in different professional categories have difficulties to define fairness, even with the majority having higher education, several years of training and expertise in the field of Public Health. This can result from the lack of interest of these professionals to update their knowledge, lack of initiative in the research area and the lack of continuous and permanent education, which should be required by employers to remain in their positions and to perform their duties at work, not occurring in practice. Through the speeches of participants in this research is perceived that a minority of professionals have an adequate perception of the
Woneska Rodrigues Pinheiro1, Francisca Moraes da Silva², Italla Maria Pinheiro Bezerra ${ }^{3}$, Hermes Melo Teixeira Batista ${ }^{3}$, Marco Akerman 4

1 Student of the Doctoral Program in Health Sciences, College of Medicine $A B C$. Professor of Nursing College Leão Sampaio. Juazeiro do Norte, Ceará, Brazil.

2 Resident Nurse in family Health by the Public Health School of Ceará. Juazeiro do Norte, Ceará, Brazil.

3 DLaboratory of Study Design and Scientific Writing. Department of Basic Sciences, Faculdade de Medicina do $A B C$.

4 Doctor specialist in Public Health and Social Medicine. PhD in Epidemiology and Public Health. Professor from the Department of Practice and Public Health of USP's. São Paulo, Brazil.

Contact information:

Woneska Rodrigues Pinheiro.

”woneska@bol.com.br 
concept of equity in health, compared to literary concepts, making crucial the development of these professionals so that they promote corrections towards providing a more just and resolute assistance.

Conclusions: It can be inferred that professionals have some knowledge about what is fair, but this concept is still vague, based on primitive human feelings and social vulnerability of the individual. A favorable position is assumed that health managers should offer to their employees, proper improvement to work in the Single System of Health level, especially in primary care, promoting means of continuous and permanent education.

\section{Keywords}

Equity in Health;

Health Promotion.

\section{Introduction}

This study refers to the process of investigation about the doctrinal principle of equity of the Unified Health System (SUS), through analysis of the theoretical and legal framework and the applicability thereof, specifically at the level of Primary Health Care (APS), since it helps in monitoring and referring the population to other levels. Initially, the reflection on this principle of SUS for construction of this study was based on a PhD research, which this research is linked, providing the basis for the development of questions and curiosities about this subject.

The Unified Health System (SUS) has been developing step by step, the first step being its regulation by Health Organic Law 8080, followed by 8142 and Basic Operational Standards, which came to change the financing of the health system and include the responsibility to act in judicial-legal implementation of the SUS to the municipalities [1].

The SUS finances not only hospital care but also outpatient care services throughout the country but also exerts typical public health functions of the state, such as sanitary and epidemiological surveillance [2].

Based on two types of principles, doctrinal and organizational, health has achieved great pro- gress, but challenges remain. Especially regarding the doctrinal (universal, Integrality and equity), as these have not been effectively implemented. Highlighting the equity, because the disadvantaged social groups are much more likely to get sick and die.

It is important to note that, the equity in access and utilization of health services depends crucially on organized health systems in order to reduce barriers of access to the population as a whole [2].

Although theoretically the SUS work to reduce assistance inequalities, the way it operates in Brazil in the three levels of care varies potentially, observing the peculiar characteristics of each region, state and city studied.

The Primary Care level, the establishment of relations with the community in its territory increases the effectiveness of the assistance provided, allowing the identification of interventions that should be given priority by forming bonds, allowing that the individualization of assistance supports care [3].

The concept of equity is sometimes treated as being similar to others, but the need for a more concrete definition makes us realize the extent of the complexity of this term.

Even though many consider equity synonymous with equality, the difference between the two words 
is much more wide-ranging. Equity therefore comes after the establishment of equality to correct the injustices that still persist [4].

The discussion of this terminology comes from the philosopher Aristotle, the oldest theoretical on the subject. Currently the conceptual definition of Whitehead is much more accepted and wideranging. It emphasizes that equity ideally involves the fact that everyone should get their best potential health conducted by a fair opportunity to access it, without avoidable disadvantages between them.

The proposal of equity as distributive justice paradigm has occupied place of relevance in the Brazilian social policy in recent years, without, however, be accompanied of the necessary theoretical disputes of this concept [5].

It is urgent, however, to define the equity we want to SUS, from which theoretical basis equity is supported by and what are the possible parameters in defining the ways that Public Health will walk in times of ethical pluralism, political and social [6].

From this context, the investigation of this study will start from following questions: "What is the concept of equity adopted by health professionals in primary care?" How do these professionals promote equity in health services where they operate?

This study is relevant because it presents the main concepts of equity used by health professionals that impact and change the health care system at the primary level, as well as these promote equity in the active health service, providing data to support future interventions. Understanding the meaning given to equity is the best way to start the planning process for its promotion, the theoretical and operational difficulties should not outweigh the importance of an equitable health care.

The SUS is one of the best health systems, which reinforces the idea to continue fighting for the final implementation of its theoretical concepts in everyday practice, constituting a challenge because there is still a great mass of the population in pover- ty and without access to good conditions essential to health.

With this study, we hope to contribute to a better understanding of the concept of health equity, helping to spread applicability and promotion of the same, as well as providing data for future studies that portray the same theme.

The assumption made in this research was that the terminological inconsistency and lack of knowledge about what is health equity would cause an inadequate and limited practice of this principle.

Based on what was exposed, this work aims: Verify the concepts conferred on health equity in the speech of professionals working in the Family Health Strategy in the city of Juazeiro do Norte-CE, Brazil.

\section{Methods}

This study's methodological approach was to perform an analytical and cross-sectional research, with a qualitative approach to obtain data that demonstrate how equity is perceived by professionals working in Primary Level, in the city of Juazeiro do Norte, Ceará, Brazil.

The analytical research is usually subject to one or more scientific questions, "hypotheses" that connect events: a supposed "cause" and "given effect" [7].

In a cross-sectional study, all measurements are made on a single occasion or for a short period of time. The data obtained from cross-sectional studies are useful for assessing the health needs of the community [8].

A qualitative research emphasizes the qualities of entities and meanings that cannot be measured by means of experiments, the social nature of reality and a close relationship between the researcher and the object of the research, observing the situations that influence the investigation [9].

The interpretation of phenomena and assigning meanings are basic tools in qualitative research, as 
it does not require the use of methods and statistical techniques. Data is collected inductively in the natural environment chosen [10].

This study was conducted with professionals working in the Family Health Strategy in a city called Juazeiro do Norte, Ceará, Brazil. The Family Health Strategy team of this city consists of 66 Basic Family Health Units, organized in 06 health districts or micro areas, according to information from the Department of Health. A simple random draw was conducted to choose the micro area to be researched and this contained 10 Family Health Teams.

The composition of this study began in February 2014, however, development and data collection were carried out from July to August of that year.

The research population was composed by health professionals working in the Family Health Strategy section surveyed in Juazeiro do Norte, Ceará, Brazil. The sample consisted of direct health care professionals in the Health Strategy that agreed to participate and sign the Informed Consent, according to the provisions of Resolution 466/12 of the National Board of Health and Ministry of Health. The project was submitted the research ethics committee, with CAAE No: 33941514.0.0000.5048.

It was used a previously structured guide with subjective questions to assist in the interview as a tool to collect the data.

Qualitative data were analyzed using content analysis method, which will be arranged by thematic categories and the data collected to characterize the studied population will be arranged in charts, tables and figures for better understanding.

In content analysis, the researcher goes into more detail on the data arising from the statistical work, in order to get answers to the questions, and seeks to establish necessary relationships between obtained data and formulated hypotheses. These are proven or refuted by analysis [10].

The interviews were recorded and transcribed by digital medium. For data analysis, we used Bardin's content analysis technique (2009).
Collected data were transcribed and soon after this they were divided into categories. From the anchor ideas such as: What is health equity for you? How do you perceive the equity in your daily practice?

Data obtained from the interviews were organized into categories to facilitate the analysis of information, where they established an articulate dialogue between the data and the theoretical references covered in this study, seeking to achieve the proposed objectives from the beginning of gathering information for the research.

\section{Results and Discussions}

It was tried to research 34 health professionals, but some of this population was excluded not composing the sample. They were excluded due to the following factors: Professionals unable to participate in the study due to the high demand for service users for professionals of the Family Health Strategy (ESF) (26.47\%), lack of professionals at the time of approach to interview at the ESF section (11.76\%), excluded for not fitting the inclusion criteria (2.94\%) and negative reply of some to join the study after taking notice of the subject $(14.70 \%)$, the same was concluded with the participation of $44.11 \%$ of the population, totaling 15 professionals for the studied sample, which was composed of doctors (D), registered nurses (RN), dentists (DT) and nursing assistants (NA).

\section{The speech of the interviewed people}

The interviewed professionals were divided by the initial letter of their profession followed by the number corresponding to each.

Data obtained from the interviews were organized into categories to facilitate the analysis of information, where it was established a clear dialogue between the data and the theoretical references covered in this study, seeking to achieve the proposed 
objectives from the beginning of the compilation for the research project.

After reading and interpretation of the data obtained in the field, it was established thematic categories from obtained categories with relation to the anchor idea, concepts of health equity were: Distribute the resources according to the individual need; Treat equal equally and unequal unequally; Confusion of concepts; Regarding the idea of promoting equity in the ESF, we had the following: There is equity and it must exist; It does not work as it should be or does not exist; Promoting equity through health education and prioritization of assistance.

Each category will be described in detail and related to the proper theoretical foundation, for better understanding of what was proposed in the objectives of this research.

\section{Defining Equity in Health}

Among the concepts given to health equity by professionals who work directly with assistance, in most speeches it is highlighted that equity is the distribution of resources according to necessity and it must first provide the universality and equality of assistance to all who seek this service specifying whether that need is clinical or epidemiological, without distinguishing which paths led that need to exist and cause damage to the health of those individuals.

Highlighted below we find the speeches of some of the interviewed professionals who corresponded to that category:

[...] it is to have equal rights for everybody, according to your needs, right?

RN2.

It is to allocate resources and attention according to the needs of each one, whoever needs it most needs more, so try to make up the difference.
According to SUS, it says you should treat each person according to his/her needs.

Equity is to give equally to each citizen according to their needs. Then, it is to give health to ensure health, to citizens in their needs in equal form to all [...].

Equity is one of SUS's principles that acts as a social justice, which judges patients differently according to the need they need.

Through these speeches is perceived that these professionals have an adequate concept of health equity, comparing the speeches of the researched participants to the studied literature. In the case of a health system with limited resources facing the ever-increasing needs, the awareness of these professionals that the equal and universal care needs corrections in order to provide a just and problemsolving assistance is fundamental.

Although the multiple meanings and understandings and equity polyphony hinder, difficult the construction of health actions and strategies for the implementation of this principle from SUS, it is believed that the values identified can serve as benchmarks for professionals and researchers in the consolidation of the Brazilian Health System as a social right. [11]

The strong sense of fairness is exactly that - to each according to his/her need - and has been considered an utopian way to manage life, particularly after the failure of global experiences that were classified communists [12].

The fact that these professionals use this kind of trial run to execute the best assistance to whom seeks care is due to the fact that there are no laws or regulations that guide the work in a different way, and for this reason they are guided by the urge to protect the "weak", one of the most primitive human feelings. 
So even not acting wrongly to treat equity as distribution of resources according to the needs of each one, the explanation of how this equity should be worked by each of us is necessary, on what criteria this explanation is based and continuity of studies on this topic.

A significant portion of interviewed professionals conceive equity as treating unequal unequally, as demonstrated by few lines below:

For me, fairness is that health is a right for all and duty of the state, and in this regard we must address the unequal unequally.

RN5.

Equity is when you treat equals equally and unequal unequally. Treat each within its inequalities.

DT2.

The horizontal equity (equal treatment for equal) that assumes the principle of equality, and the vertical equity (unequal treatment for unequal) which assumes that equal treatment is not always fair. [13] The concept of horizontal equity suffers a little when you consider that, when it comes to health issues, patients in similar situations are never found; in this case, it will always be more equitable to provide better care to the more vulnerable patient.

The notions of equality and inequality refer to specific dimensions of analysis, to the extent that they can all be considered equal to the other if taken by a generic characteristic enough to be extended to either; or may be considered completely unequal, if compared by restrictive condition that results in an almost individualization [14]. The quality of being equal or unequal has only a descriptive character, without association required with a value judgment about justice or injustice.

There is a cry for justice in health, expressed as a minimum formal application, common in theories of justice: the equal should be treated equally and unequal should be treated unequally. [15]

It can be seen that the main problem of this concept and many others related to theories of justice imply in the absence of materiality, a legitimation, a specification that shows in which aspects individuals are equal or unequal, which needs are prioritized and what reason, being the performance of these professionals still grounded in little explanatory concepts and primitive feelings of protection and prioritization of assistance to the most vulnerable.

Other lines found in the interviews demonstrate confusion with other principles of SUS. The following statements clearly demonstrate this fact:

For me it is the person having good hygiene habits and be aware, education is the preventive part, which unfortunately does not exist here in our reality.

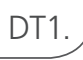

For me health equity is cleaning, you know, to get medication, get food, get education, leisure, all of this.

NA1.

Um, for me is equilibrium between us nurses, the community health workers, the dentist, even if I do not have a doctor, all being in harmony to better serving the community. For me that's all.

Equity is one of the most beautiful things we see in SUS with regards to the right for equality of assistance to all those looking for the Unified Health System, but in practice is not quite how it works.

The guarantee of health services for all.

The notion of fairness (equity) is associated differently to equality and, above all, to justice, in order to provide the correction of what equality knocks about and, therefore what justice must accomplish. Taken in this sense, equity requires equality to produce effects, because it constitutes precisely as a broker of the equal status, to the extent that the 
adoption of this feature proves imperfect before the objectives of promoting [4].

The equity concept is connected to the universal right; we will have meaning to the answers. If this notion of automatic right to health, education and other social protection policies is not accepted, the criteria for assessing equity will be others. Therefore, it is important to reconstruct the network of relationships in which the term equity would be insured. The meaning and the significance of the term equity are modified according to the value system, the idea of social organization and even economic and social development that each speech refers to [12].

The diversity of meanings for equity is the result of the complex reality we live in and therefore the equity should be analyzed as a complex and dynamic object, in which all stakeholders, professional researchers and users of SUS should be heard and considered in the planning of actions in health [6].

It is exciting to realize that there is a political and social commitment to build a health system based on the rule of justice and concerned about social inequality, even if the mishaps in this walk are countless, taking in consideration the theoretical and conceptual challenges and also challenging practices placed to producers of knowledge and health management centers [4].

It is believed we are no too far from the equity we want, but to reach it, we must fundamentally define which concept applies best in the health field, establish decision criteria and priority needs so we can have health present in a more equal phase, as these generic concepts present in this and previous categories despite facilitate the understanding of what is fairness, it does not facilitate at any time its practical application.

You can see in the interviews, that all professional categories have difficulties to conceptualize equity, which may result from the disinterest of these professionals to update knowledge, lack of initiative in the research area and the lack of continuous and permanent education, which should be required for professionals to keep their role and perform their duties, not occurring in practice.

The need for the continuation and multiplication of researches on the subject of health equity is evident, expansion of research and concrete definition of the measurement of inequality mensuration, in addition to the inclusion of this principle in the current legislation in a clear way, so that we have the SUS even closer to what we want.

\section{Promoting health equity in ESF}

This study analyzed the speech of the interviewed people related to the promotion of health equity in the ESF by the professionals working in it. As highlighted in the following lines:

Equity is one of the principles of SUS and is part of our necessity. It has to be fulfilled. Along with the universality and integrality of service they contemplate SUS's principles. So it is a step that cannot be sacrificed in any way, it has to be met, in all its completeness.

You can observe within the universe of system users who needs more care. Who is that person who really needs more? Then you can make a bit easier for that person to get access to the service.

DT2.

Thus, with respect to the population I believe there is such equity. Why? Because with them we try to, mainly because this is SUS, to treat in a way they have access to this service, what we cannot offer here they can have the service done at the Center for Dental Specialties; this is something that years ago did not exist, and there is acceptance and this population can use this service. Another thing, the multidisciplinary team too, because sometimes only doing your part is not enough, but we have to have other professionals engaged, the rest of the team. I believe that this exists here.

DT1. 
I believe in the matter of giving priority to patients, the elderly, pregnant women, sometimes the patient has the question of urgency, acceptance of service, after the acceptance we observe the ones of urgency and we try to put them first, then the neediest we try to look at them in a different manner and try to fit them in the best possible way.

RN5.

In our family health program we have various types of patients, we have bedridden patients, we have patients with psychological illnesses, with various types of psychological disorders, and it is in this way that we treat them a little unequal. And there are also the patients who come only for consultations, which are patients without a disease, they are only there to follow up with a professional about previous health issue, mothercraft, prenatal assistance, and we have to deal with these people differently.

NA3.

From these statements, we notice that professionals recognize the importance of applying the equity in assistance provided to the population and that in the midst of insufficient resources it is still possible to implement it. They also recognize the importance of equity at the level of Primary Care, by claiming that this is the gateway to the health system.

To reverse a situation that is considered unjust will depend, necessarily, on the diagnosis made at the closest level to the citizen (city, neighborhood, district, coverage areas) and stakeholder involvement in setting priorities [16].

Health policies that have equity as a principle and as objective must articulate epidemiological parameters with social and economic parameters that allow the characterization and prioritization of vulnerable groups. In the contemporary Brazil the equitable social policies must modify the targeted distribution rules to favor and promote the economically vulnerable social groups [16].
Ferraz and Vieira (2009), in this context, which is simply impossible to give unlimited assistance to all, the principle of equity requires that the scarce resources are allocated in order to prioritize the reduction or elimination of differences between individuals that come from avoidable and unjust factors.

There is a track of a specification in the speeches after speaking in meeting the needs of people and prioritize those most in need, but there is the persistence of lack of substance to define needs and needy [17].

Despite adequate and optimistic thoughts about the promotion of equity, the issue of prioritizing some socially unfavorable groups needs to be expanded, because population which already have a legitimate health policy do not need this individualized treatment (the elderly, women and children). There are other groups that also have particular needs and therefore need a different treatment by health care providers. These include people in the LGBT group (gays, lesbians, bisexuals and transgender), black people, people on the streets, indigenous, gypsies, religion practitioners of African origin, rural population, the disabled and all people that have some feature that results in a biased way of relating in society.

Some of the interviewed professionals proved to be aware of the discrepancies between the theory and the practice of equity, as shown in the following speeches:

I realize it does not exist here (laughs). I realize we lack equity, beginning with management, who address all teams from the family health sector alike. For example, this cannot be done. I work here in this highly volatile area, it is the most violent neighborhood in Juazeiro do Norte and I am treated as a nurse working in the center unit, then there is no equity. In a different health unit there are four pregnant women, here I have fiftyseven. So there is no equity from management, then if there is no equity with us it is very difficult for us to reproduce it in the community, because we do not have support. This is reality. 
It does not work as it should be, according to that need, especially here in the neighborhood I work where there is a huge need, more than, not that everyone has their rights and needs, but only that they are not treated equally depending on their needs, then, equity actually in the book, the theory is very beautiful, but in practice it does not work as it should be.

RN2.

And we know that there are people who would get a request and go to the office, and talk to so and so, with someone, or someone else, or is related to, or would start a fight just to end up getting the exam done. Then the equity at this time goes down the drain, isn't it? because the right would be if the system works properly and everybody who comes in, who has the right to have a treatment, be entitled to all the steps of this service so we can make the diagnosis, care for a condition that a patient would have. So actually, in practice it does not work properly.

[...] Give priority to a patient when the doctor puts an urgent note, and yes pass the patient in front of the others.

The statements above literally denote the revolt of some professionals when they cannot provide an equal service due to lack of resources or the failure of management in allocating resources to each health unit. The illegal methods that system users use to obtain actions and health services are enhanced, causing damage to the community and equity. It is also noted only the presence of clinical criteria for the prioritization of care in the speech of one of the professionals. In fact, this thought is limited, noting that people, after seeking public health services, should not be classified only by the condition, but also by the presence of characters that undermine the sociability of the individual and access to its full potential health.
The range of equity, therefore, would imply in promoting a redistribution of goods and services determinants of health in order to deal with these differences - which would mean prioritizing the disadvantaged people [5].

On the means of promoting equity present in the interviews, two ways prevailed: health education and the prioritization of assistance, as analyzed in the statements below:

It's just to see that if this person has a number of procedures that would need more of you then you attend this person first, usually, this facilitates the scheduling of that person. When the person, for example, would need you to work more with her/him the question of health education, you will note that this same person has a greater need; you focus more on that, isn't it? We end up performing in various ways trying to give exactly to that person who has less opportunity slightly more opportunity.

Here we do lectures, we work with health promotion in a center that we have here at the church, in the church hall, we do lectures there, lectures here, we try to promote health.

NA1.

We do in the nursery, we do supervised education, we organize oral hygiene instructions, we take those kits to distribute, brushes, toothpaste, we do educational lecture.

Look, well, we've done some education in health sometimes, did you know? We've done in every way; we did children's education, already done on Mother's Day, every time aimed to health education. Well, this is evrything. 
We have the issue of health education groups, that we organize, the need from each one, an example we have right now is this one: the name was given to the doctor but the doctor did not come, so I would let the patient go as there are several duties that the nurse cannot perform as it is the doctor's responsibility and you're hands are tied, but the patient is in so much need that sometimes we even run the risk and get it done, try to at least solve that need of the hour in accordance with the nursing law to be able to respond to the patient so he/she can get discharged at least with minimal satisfaction, because the health system as we know in Brazil, not only in the main cities, is not working as it should be.

RN2.

Let's assume. The patient comes here, and has a dental cavity. Another arrives and needs a root canal. The third arrives and needs a periodontal treatment. I have to give and to ensure that treatment is done properly. With information from patients I will assess the needs, and I will give priority, I will thereby work according to equity. I will work on one and then on another, in a way to ensure a decent treatment for every citizen looking to get something done by me. From my point of view this is it, working with equity.

DT3.

We realize activities according to the ages and needs. We seek to promote health lectures for adolescents, pregnant women and elderly.

RN6.

From these speeches, it is assumed that professionals understand that the tuition of the population through educational lectures contribute to the applicability of equity, therefore making them aware regarding the prevention, promotion and rehabilitation of health, individuals will find autonomy to fight for their rights.
Equitable public policies should be based on recognition of health as a right, the prioritization of needs as an essential category for the forms of justice and the establishment of corresponding financing mechanisms [16].

Popular Education in Health (EPS) has been the methodological policy framework guiding many health professionals in developing their practices within the primary health care. At the same time it is confirmed that the EPS, as a policy, expresses the following as a presupposition: the expanded comprehension of health and critical understanding of the social determinants so that each subject realizes which world they live in and their ability to act to change this world [11].

The health equity issue provides us with the design of a new view of health, on individuals and on society. Even with a considerable amount of literature addressing this issue, there is a real need for more research to be done in order to define precisely this concept and how it will be applied, beyond the formulation of criteria for setting priorities.

It can be inferred with this study that the professionals have some knowledge about what equity in health is, but this concept is still vague, based on primitive human feelings and social vulnerability of the individual, when this term should be broad and holistically address the individuals.

You can see that the interviewed professionals in this study restrict the prioritization of assistance to groups whose inclusion policies have already taken root, not being observed at any time the concern of the same with other groups that have particular characteristics that affect their access to health care, for example, LGBT people, black people, gypsies, indigenous, rural population, people of African roots religions, people on the streets, among others. These are the groups that currently need to receive a treatment from health professionals with a different perspective. So if these professionals do not reconcile this idea to their knowledge, it is believed that the principle of fairness (equity) would never advance 
because the treatment that these people will receive will be inappropriate, as these would be unprepared professionals to serve the patients.

Even with the majority of the interviewed with a higher education, we can see the ignorance and theoretical-practical difficulty of fairness from all professional categories, including those with expertise in the area of public health policies and many years of academic training. The lack of update in the areas of activity of surveyed employees is noted, being responsibility of the professionals themselves to look for new literature and of managers to ask employees and supply ways of improvement for their team.

It is important to note that the action of serving people according to their needs should be reviewed, because there are no concrete methods of measuring inequalities that can guide us on which needs we should focus the assistance. Hence the importance of continuing the studies about equity for the legitimate formulation on how to provide justice in health.

The assumption made in the beginning of this study was confirmed, that the practice of equity in primary care is being inadequate and limited considering the terminological inconsistencies and lack of knowledge of this principle by professionals.

Finally, it is suggested that the research on health equity continues to grow, in order to provide the best theory and the best way to promote equity, optimizing the available resources, the allocation of resources and access to health services to all users in need.

\section{List of abbreviations}

APS: Primary health care

EPS: Popular education in health

ESF: Family Health Strategy

LGBT: Gays, Lesbians, Bisexuals and Transgender

SUS: Unified Health System

\section{Conflicts of interest}

The authors declare that there is no conflict of interest.

\section{References}

1. Silva, M. G. C.; Sousa, M.H.L (Org) Temas de economia em saúde. Fortaleza: UECE/Expressão, 2005.

2. Travassos, C.; Castro, M. S. Determinantes e desigualdades sociais no acesso e na utilização de serviços de saúde. In: Escorel, S.; Lobato, L. V. C.; Noranho, J. C.; Carvalho, A. I. (Org)- Políticas e sistema de saúde no Brasil. Rio de Janeiro: Editora Fiocruz, 2008

3. Nivaldo - Junior, C.; Jesus, C. H.; Crevelim, M. A. A Estratégia Saúde da Família para a equidade de acesso dirigida à população em situação de rua em grandes centros urbanos. Saúde e Sociedade. São Paulo, v. 19, n. 3, p. 709-716, 2010.

4. Elias, P. E. A utilização da noção de equidade na alocação de recursos em tempos do pensamento (neo) liberal: anotações para o debate. Ciência e Saúde coletiva, 10(2): 287-297, 2005.

5. Backx, S. S. Equidade, desigualdade e iniquidade em saúde: mote contra o projeto de universalidade. II Jornada Internacional de Políticas públicas, São Luís do Maranhão, 2005. Acesso em [20 de março de 2015]. Dispinível em: http://www.joinpp. ufma.br/jornadas/joinpplII/html/Trabalhos2/Sheila_de_Souza_ Backx254.pdf

6. Granja, G. F.; Zobolli, E. L. C. P.; Fortes, P. A. C.; Fracolli, L. A. Equidade no sistema de saúde brasileiro: uma teoria fundamentada em dados. Revista Baiana de Saúde Pública, v.34, n.1, p.72-86, jan./mar. 2010.

7. Pereira, M. G. Epidemiologia: teoria e prática. 1. Ed. Rio de Janeiro: Guanabara Koogan, 2008.

8. Beaglehole, R. B.; Kjeiltrôn, T.; Cesar, J. A. Epidemiologia básica. 2. Ed. São Paulo: Santos, 2011.

9. Denzin, N. K.; Lincoln, Y. S. O planejamento da pesquisa qualitativa: teorias e abordagens.2 ed. Porto Alegre: Artmed, 2006.

10. Markoni, M. A.; E. M. Lakatos. Fundamentos da Metodologia científica. 6 ed. São Paulo: Atlas, 2009.

11. Granja, G. F.; Zobolli, E. L. C. P.; Fortes, P. A. C.; Fracolli, L. A. O discurso dos gestores sobre equidade: um desafio para o SUS. Ciência \& Saúde Coletiva, 18(12): 3759-3764, 2013.

12. Campos, G. W. S. Reflexões temáticas sobre a equidade e saúde: o caso do SUS. Saúde e Sociedade, v.15, n.2, p.23-33, maio-ago 2006.

13. West, P.; Cullis, J. Introdución a la Economia de la Salud. Oxford, 1979.

14. Silva, M. G. C.; Sousa, M.H.L (Org) Temas de economia em saúde. Fortaleza: UECE/Expressão, 2005. 
15. Zobolli, E. L. C. P.; Fracolli, L. A; Granja, G. F.; Equidade no SUS: em construção uma concepção política de justiça em saúde. Revista Bioethikos - Centro Universitário São Camilo, 4(2): 180 188,2010

16. Escorel, S. Os dilemas da equidade em saúde: aspectos conceituais [homepage da internet.]. Brasília: OPAS, 2001 [acesso em 30 de março de 2014]. Disponível em: http://www. opa.org.br/observatorio/Arquivos/sala256.pdf.

17. Ferraz, O. L. M.; Vieira, F. S. Direito à saúde recurso escassos e equidade: os riscos da interpretação judicial dominante. Revista Ciências Sociais, 52(1): 223-251, 2009

18. Breveman, P. Helth Disparities and Health Equity: concepts and measurement. Annu. Rev. Public Health, v. 27, p. 167-194, 2006.
Comment on this article:

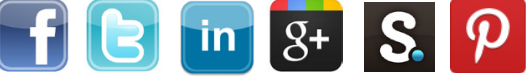

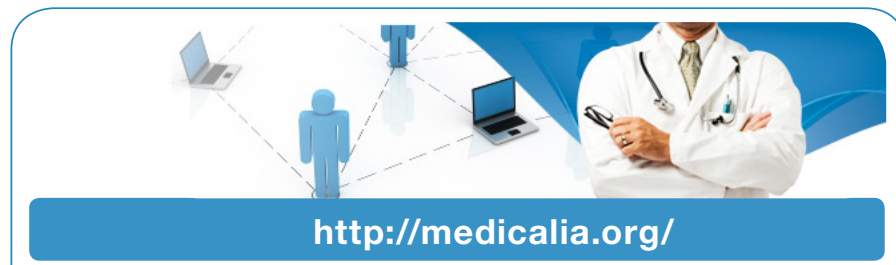

Where Doctors exchange clinical experiences, review their cases and share clinical knowledge. You can also access lots of medical publications for free. Join Now!

\section{Publish with iMedPub}

http://www.imed.pub

International Archives of Medicine is an open access journal publishing articles encompassing all aspects of medical science and clinical practice. IAM is considered a megajournal with independent sections on all areas of medicine. IAM is a really international journal with authors and board members from all around the world. The journal is widely indexed and classified Q1 in category Medicine. 